\title{
Participatory Environmental Valuation: A Comparative Analysis of Four Case Studies
}

\section{Leslie Carnoye ${ }^{1, *}$ and Rita Lopes ${ }^{2}$}

1 Clersé - Centre Lillois d'Etudes et de Recherches Sociologiques et Economiques, Université des Sciences et Technologies de Lille, Université de Lille 1, Bâtiment SH2, Villeneuve d'Ascq Cedex 59655, France

2 CENSE - Center for Environmental and Sustainability Research, Faculdade de Ciências e Tecnologia, Universidade Nova de Lisboa, DCEA FCT-UNL, Caparica 2829-516, Portugal; E-Mail: rj1@fct.unl.pt

* Author to whom correspondence should be addressed; E-Mail: leslie.carnoye@ed.univ-lille1.fr; Tel.: +33-320-436-640; Fax: +33-320-436-635.

Academic Editors: Olivier Petit and Géraldine Froger

Received: 28 February 2015 / Accepted: 20 July 2015 / Published: 23 July 2015

\begin{abstract}
The valuation of multiple ecosystem services requires the design of valuation processes able to integrate different dimensions of value and to cope with complexity. Following the "value-articulating institution" framework, we note that three core problems arise: the cognitive, normative and composition problems. Combining valuation methods, such as contingent valuation and multicriteria analysis, with participatory and deliberative techniques is increasingly promoted as a means to address those fundamental problems. However, the quality and legitimacy of the valuation process then becomes dependent on how participation is framed. We note that numerous issues need to be taken into account, such as the roles assumed by participants, the differences in contribution among participants, the level of participatory impact and the level of democratization of the decision-making process. This paper proposes a detailed qualitative analysis of four case studies, each of them having implemented a specific valuation method in a participatory process. We analyze how those cases were handled in each of the dimensions considered and offer our conclusions about the added values and remaining challenges related to participatory environmental valuation.
\end{abstract}

Keywords: environmental valuation; ecosystem services; value-articulating institutions; participation; deliberation; decision-making 


\section{Introduction}

Increasing human pressure on the environment emphasizes the need to make explicit why the environment matters and how it can be taken into account in public and private decision-making. Within academic research and in political agendas, this concern is currently framed as the need to value ecosystem services $[1,2]$. The ecosystem services metaphor is criticized for its reductionism, as it tends to neglect the complexity of the relationships and interdependencies within functioning ecosystems and between ecosystems and socioeconomic systems $[3,4]$. However, the simultaneous valuation of multiple ecosystem services puts the recommendations of previous research results into practice, according to which environmental valuation should take into account multiple dimensions of value, without reducing them into one single scale [5]. This valuation debate has been a core issue in ecological economics [6,7] and it derives from more fundamental criticism leveled by ecological economists upon the flawed behavioral models of the rational individual in neoclassical economics $[8,9]$.

This paper is not focused upon the various definitions and interpretations of the ecosystem service concept, which remains problematic [10-12], but it focuses instead on recent advances and remaining core issues regarding methods for environmental valuation. We develop an institutional perspective on environmental valuation, following the "value-articulating institution" framework [13-16]. We also draw insights from the participatory literature [17-19], as well as from the "deliberative ecological economics" research agenda $[8,9]$. The common ground of those approaches is to insist on the need for developing public and stakeholder involvement in environmental valuation, on the basis of a shared institutionalist perspective, according to which choices made about the environment take into account both collective and individual preferences, which are socially constructed through norms, rules, conventions and institutions [9,14].

The concept of "value-articulating institutions" emphasizes that valuation methods are sets of rules framing the valuation process (e.g., who is involved, what is data, how stakeholders articulate their preferences, etc.). This framework allows us to define three basic issues occurring when valuing the environment: The cognitive, normative and composition problems. We view these issues as fundamental, which means that they can never be completely eliminated. However, different valuation methods, such as monetary valuation and multicriteria analysis (MCA) present major differences when confronted with those three problems. The value-articulating institution perspective highlights that combining methods, especially monetary valuation and MCA with participatory approaches, is a credible means to reduce these methods' shortcomings.

Recent advances in the participatory literature also highlight the importance of participation to address complex and dynamic environmental problems [17], as well as the need to combine different approaches to capture different value dimensions [19-22]. From a similar standpoint, the field of "deliberative ecological economics" advocates for deliberative valuations to improve the quality of sustainable decision-making because deliberative processes are assumed to be more legitimate, fair and democratic [8,9].

Known methods such as deliberative monetary valuation [23] and social multi-criteria evaluation [24] represent such attempts to improve environmental valuation by combining traditional methods with participatory features. However, numerous issues remain regarding the implications for ecological and economic sustainability of using participatory approaches and deliberative methods [14,15,25]. For the 
purpose of this paper, we focus on four main issues: The roles assumed by participants, the differences in contribution among participants, the level of participatory impact, and the level of democratization of the decision-making process. Those criteria were designed based on the literature with regard to the information available in the cases studies considered.

To foster learning from empirical evidence, this paper proposes a qualitative comparative survey based on these four case studies, in which four different types of valuation methods were implemented with different participatory features. We selected the following cases on the basis of a literature review: In case $A$, focus group sessions were implemented before contingent valuation (CV) surveys [25]; in case B, the elicitation of willingness to pay (WTP) was done in a citizen's jury context [26]; in case C, various participatory methods (interviews and group talks) were combined with a CBA phase and a deliberative MCA phase [27]; and in case D, a MCA was realized in a stakeholder's jury setting [28]. Through this qualitative survey, the considered case studies are each equally valued as original research experiments, each having its own advantages and limitations. The qualitative methodology we used allowed us to better understand the relationships between the valuation methodologies that were used, the particular logics of the appraisals and the choices made by the research teams, as well as the specific institutional contexts in which they took place.

Section 2 develops the analytical framework that was used, and Section 3 is dedicated to the case study analysis. Section 4 concludes on the added values and challenges related to participatory environmental valuation.

\section{Analytical Framework}

\subsection{The Cognitive, Normative and Composition Problems and the Value-Articulating}

\section{Institutions Perspective}

Environmental valuation is about formulating a choice over the consumption or preservation of environmental resources and attributes. In that process, social, economic and biophysical values are tightly interrelated: Both the biophysical consequences of the decision or project under valuation and the social appreciation of those consequences matter. According to Vatn, three types of problems arise during an environmental valuation [14].

First, there is a "cognitive" or an informational type of problem related to the difficulties in observing and weighting environmental attributes because ecosystems are characterized by a "functional invisibility" [14] (p. 308). This complicates the communication process and the emergence of a mutual understanding over what exactly needs to be valued. The cognitive problem challenges the assumptions of neoclassical economic theory, in which individuals are assumed to have known preferences, and emphasizes instead that participants and decision-makers often have to build their preferences during the process through improving their understanding of the objects under valuation.

Second, environmental valuation triggers a "normative" problem: that of (in)commensurability. Commensurability assumes that biophysical, social and economic values can be reduced to a single scale, implying the strong comparability of values either in ordinal (weak commensurability) or cardinal (strong commensurability) terms [5]. Assuming commensurability (i.e., strong comparability) implies that individuals involved in the valuation process (participants and analysts) are able to do this operation 
or believe that it can be done. However, various ethical and moral dimensions as well as commitments and judgments can preclude commensurability and challenge the reductionist perspective on valuation (which applies for both economic and biophysical metrics). Environmental valuation processes can be designed to support incommensurability if the absence of a common scale of measurement is recognized: incommensurability does not imply incomparability, but weak comparability remains useful [5]. Taking incommensurability seriously also implies the recognition that different values cannot always be traded off against each other, or that there are limits to such trade-offs. In that sense, during a valuation process, the normative problem is connected with assumptions regarding compensability: i.e., the idea that a loss in one type of value can be compensated for by gains in other types of value [5,24].

Finally, the third issue is the "composition" problem. It has to do with the "functional indivisibility" [14] (p. 308) of ecosystems. Indeed, ecosystems are functioning systems and processes characterized by complex interdependencies, irreversibility and threshold effects. In a system, trying to value components separately from the whole to which they belong, or assuming that those components can be traded off against each other is not relevant. Yet valuing nevertheless requires bundling the object under valuation. There is therefore a conflict between the holistic character of the objects under valuation and the finite nature of environmental valuation processes. Thus, compromises must be made during the valuation process about the degree of ecological complexity included in the analysis. This compromise is reflected in the choice of the ecological indicators and in their design. Taking the composition problem seriously implies a form of reflection upon the way that the objects under valuation are framed and upon the choice of the subsequent ecological indicators.

Defining valuation methods as "value-articulating institutions" emphasizes that: (1) Different valuation methods imply different forms of participation: who participates, in what capacity (e.g., as a consumer or as a citizen) and how (e.g., in a written form, orally, individually or collectively etc.); (2) Valuation methods differ in terms of what is considered data (e.g., observed prices, price bids, biophysical units, weights, arguments etc.); (3) They differ also according to the ways in which data and values are treated and articulated (i.e., how data are produced and weighted, aggregated or agreed upon during the process). As a result, "the process frames the outcome": Different types of valuation methods, such as contingent valuation (CV), cost-benefit analysis (CBA) and multi-criteria analysis (MCA), do not equally address the cognitive, normative and composition problems [15].

$\mathrm{CV}$ and CBA rely on core hypotheses of the standard neoclassical model, where the key unit of analysis is the individual, framed by the behavioral model of rational choice. Preference utilitarianism implies strong assumptions regarding not only "what a choice is" (individual calculation, trade-off) and "how choices are made" (preferences are already given, commensurability is not questioned) [29,30] but also "what the environmental characteristics are" (externalities or commodities often unaccounted for in real markets). Typically, those methods do not adequately address the three core problems involved in environmental valuation [15], but they remain commonly promoted, partly for theoretical and sociological reasons, and partly for more pragmatic beliefs. Indeed, neoclassical economics remain largely dominant today, which explains that despites their major failings, CV and CBA remain viewed as more "objective", "systematic" and "scientifically well-grounded" methods. Furthermore, it is increasingly assumed that decision-makers speak the language of money and that they demand assessments based upon efficiency, on the basis of an evaluation of benefits and costs [4]. 
MCA stems from system analytics and can also be framed as an optimization process. However, the major difference is that MCA can be based on very different assumptions regarding commensurability, compensability and aggregation [5,24]. MCA typically offers interesting possibilities to address the cognitive problem because it allows precise structuring of the valuation in an impact matrix incorporating criteria, policy alternatives and weights. It can also be designed to address the normative problem if weights are designed as coefficients of importance [5,30,31], which is the case in outranking methods. However, a greater emphasis is placed upon how the problem considered can be deconstructed (i.e., how the favored alternatives may change according to variations in weighting), which may lead to difficulties in reaching a final decision. Furthermore, when the choice over a policy strategy involves several decision-makers, the process of aggregating or articulating weighting preferences is a delicate operation.

The value-articulating institution perspective emphasizes that participation can help to reduce the shortcomings of $\mathrm{CV}, \mathrm{CBA}$ and MCA and to better address the cognitive, normative and composition problems in environmental valuation. This is what we aim to assess by comparing the selected case studies. However, as the following section underlines, participatory formats have their own limitations and some issues should be handled with great care.

\subsection{Participatory Environmental Valuation: Advances and Challenges}

Participatory methodologies can assume either a non-deliberative approach or a deliberative approach. Non-deliberative methods include surveys, polls, public comments, public information sessions and public hearings, while deliberative methods include focus groups, citizens' juries, consensus conferences, deliberative monetary valuation, social multicriteria evaluation, advisory committees and visioning workshops [19,32]. Deliberation implies that all participants are gathered in one place with the explicit purpose of debating and exchanging information, ideas and arguments about the problem considered, after which either a final decision is made or the process is repeated.

Fundamentally, the quality and legitimacy of the outcomes of participatory valuation processes are heavily dependent on the choices made regarding the participation setting [17]. Indeed, participation "faces a world of choices" [19] (p. 21); and those choices influence all of the key dimensions of value-articulating institutions (who is involved, on what premises, how data are produced, etc.) as well as the outcomes of the valuation studies and their relationships to formal decision-making structures. Based on Videira et al. [19] and Zografos and Howarth [9], we propose a set of criteria useful to analyze complex participatory valuation experiments. The criteria were adapted from the literature to the selected case studies. The goal was to focus the analysis on a narrowed-down set of basic criteria that would allow us to exploit all of the information available in our empirical material, while avoiding redundancies in the comparison.

The first criterion playing an important role in participatory processes is the roles assumed by the participants. Indeed, participants can be addressed as consumers, as citizens or as stakeholders. In this paper, we define a stakeholder as an actor having a specific personal or professional interest in the environmental issue considered, or acting as a representative of the collective interests of a formally constituted group [33]. This can include both representatives of the political authorities in charge of management and other groups of stakeholders. By contrast, citizens are members of the broader public and act as representatives of the general interest. The issue of the role assumed by the participants is 
related to the basic question of who should be involved in the valuation, depending on the objectives of the study, the type of method applied and the context. This issue is connected to the identification of all relevant participants, to the representativeness of the valuation towards the general population and in fine to knowing who gets a voice through the overall valuation and how.

The second criterion assesses the differences in contribution between the participants. In complex participatory exercises, those differences can be related to the different stages at which various participants or groups of participants are involved in the process (e.g., during early stages only for problem scoping, or for designing indicators and policy alternatives, or during the assessment and the decision-making process, or afterwards for monitoring, etc.). Differences in direct contributions of participants during the assessment and decision-making stages are also included. The point is not to maintain in all cases a norm of equity in contribution among all participants; maintaining differences can be justified by the logic of the process. However, it remains an essential dimension to take into account when assessing the fairness and legitimacy of participatory processes, and it has strong implications on the quality of their outcomes.

Drawing from Arnstein's ladder of participation [32], Videira et al. [19] define five levels of participatory impact, ranging from information through consultation, involvement and collaboration to self-determination. This constitutes our third criterion. The level of participatory impact reflects the degree to which participants can determine the end product of the process, and it is associated with the orientation of informational flows between participants (e.g., one-way or two-way flows). It determines the types of outcomes of the valuation exercise (i.e., if the participants had an influence on decisions, or on the design of the alternatives, or if they were able to make the decision itself).

Finally, the last criterion is related to the level of democratization of the decision-making process. Indeed, deliberative valuation methods are based on the normative claims of deliberative democracy, which criticize technocratic power and the mechanisms associated with representative democracy, to advocate instead that the direct and active engagement of citizens, through debates and a reflection upon preferences, is at the core of the legitimacy of public decisions. Furthermore, the underlying logic is that a deliberative process forces participants to think in terms of the general interest, which is likely to insure a stronger consideration of ecological issues [9,34]. Therefore, insofar as deliberation is promoted as a means to improve environmental valuation and decision-making, this is an important dimension to take into account.

The assessment of participatory outcomes can include other social goals such as learning, the inclusion of public values and preferences in decision-making, the potential to foster trust in institutions and the reduction of conflict between stakeholders [19]. However, those criteria were either difficult to assess on the basis of the information available in the case studies considered or redundant with other parts of our analysis.

\section{Comparative Analysis of the Case Studies}

\subsection{Presentation of Cases}

Table 1 presents the four cases analyzed. The value-articulating institution framework is used to identify key steps of the valuation processes and to establish a comparative grid for analysis. Reading Table 1 in columns allows a comprehensive understanding of each case, while a second reading following the rows provides interesting comparative insights. 
Table 1. Case studies comparison based on the value articulating institution framework.

\begin{tabular}{|c|c|c|c|c|}
\hline & $5]-A$ & {$[26]-B$} & 27]-C & chsler $[28]-D$ \\
\hline $\begin{array}{l}\text { Contexts and } \\
\text { objectives of } \\
\text { the study }\end{array}$ & $\begin{array}{l}\text { Objectives of the study: Ecosystem } \\
\text { services are generally unaccounted for in } \\
\text { decision-making causing ecosystem } \\
\text { degradation. Assessing the economic } \\
\text { efficiency of restoration projects: } \\
\text { Identifying which restoration scale } \\
\text { provides the greatest cost-benefit ratio. } \\
\text { Environmental problem: Restoration of } \\
\text { riparian areas along the Little Tennessee } \\
\text { River (LTR), North Carolina. } \\
\text { Methods: CV/CBA associated with } \\
\text { focus groups }\end{array}$ & $\begin{array}{l}\text { Objectives of the study: Incorporating } \\
\text { community values into environmental } \\
\text { decision-making; improve the robustness of } \\
\text { WTP values in CV/CBA. } \\
\text { Environmental problem: Management } \\
\text { activities of national parks supervised by the } \\
\text { National Parks and Wildlife Service in New } \\
\text { South Wales, Australia. } \\
\text { N.B. This case is focused on methodological } \\
\text { dimensions. No real decision-makers were } \\
\text { involved and it was presented as fictional to } \\
\text { the jury. } \\
\text { Methods: Deliberative monetary valuation, i.e., } \\
\text { CV implemented in citizen's jury context. }\end{array}$ & $\begin{array}{l}\text { Objectives of the study: Uncertainty and } \\
\text { ecological complexity, flaws of CBA, } \\
\text { decision-making quality, competence and } \\
\text { fairness, stakeholder implication. } \\
\text { Environmental problem: Water allocation } \\
\text { conflict between locations } \\
\text { (up-stream/down-stream) and users in the } \\
\text { Spree River watershed, Germany. } \\
\text { Methods: Integrated Methodological } \\
\text { Approach (IMA) combining a large } \\
\text { participatory process, CBA (single-criterion } \\
\text { assessment) and deliberative MCA as } \\
\text { different steps of the same process. } \\
\text { N.B. Only the CBA was realized when } \\
\text { the paper was published. The MCA is } \\
\text { only described. }\end{array}$ & $\begin{array}{l}\text { Objectives of the study: Identifying and } \\
\text { prioritizing between ecological, } \\
\text { economic and social dimensions; } \\
\text { deciding upon a suitable and sustainable } \\
\text { management strategy for tourism and } \\
\text { recreational activities. } \\
\text { Environmental problem: Severe } \\
\text { environmental problems, including water } \\
\text { allocation issues, caused by the annual } \\
\text { influx of tourists in the Goulburn Broken } \\
\text { Catchment of Victoria, Australia. } \\
\text { Methods: Social multicriteria evaluation } \\
\text { i.e., MCA implemented in citizen's } \\
\text { jury setting. }\end{array}$ \\
\hline $\begin{array}{l}\text { Elements under } \\
\text { valuation }\end{array}$ & $\begin{array}{l}\text { Ecosystem Services: Habitat for fish } \\
\text { (abundance of game fish), habitat for } \\
\text { wildlife (in buffer zones), erosion control } \\
\text { and water purification (clarity), } \\
\text { recreational uses (allowable water uses), } \\
\text { ecosystem integrity (index of } \\
\text { naturalness); five restoration } \\
\text { programs/scales considered (current, } \\
\text { small streams, small streams }+2 \text { miles, }+4 \\
\text { or }+6 \text { miles) }\end{array}$ & $\begin{array}{l}\text { Five management activities: Fire management } \\
\text { (number of parks with good fire } \\
\text { management), weed control (area controlled } \\
\text { per year), feral animal control (area } \\
\text { controlled per year), maintenance of visitor } \\
\text { facilities (proportion of well-maintained) and } \\
\text { management of historic sites (number of } \\
\text { well-protected). }\end{array}$ & $\begin{array}{l}\text { Long term variations ( } 50 \text {-year projections) } \\
\text { of net economic benefits for fish farming; } \\
\text { lake tourism; public water management and } \\
\text { lake water treatment and for ecological } \\
\text { indicators such as mean water availability } \\
\text { for minimum flow; average water flow for } \\
\text { Berlin and for Spreewald. Five alternative } \\
\text { management options and two scenarios } \\
\text { (one taking into account climate change) } \\
\text { are considered. }\end{array}$ & $\begin{array}{l}\text { Ecosystem Services (water quality and } \\
\text { quantity, biodiversity, aesthetics); social } \\
\text { and cultural (public access to sites, jobs, } \\
\text { cultural heritage and education) and } \\
\text { economic dimensions (costs and } \\
\text { benefits). Indicators include quantitative, } \\
\text { qualitative indexes (scale of value) and } \\
\text { binary indexes (presence or absence). } \\
\text { Five alternative management options } \\
\text { are considered. }\end{array}$ \\
\hline
\end{tabular}


Table 1. Cont.

\begin{tabular}{|c|c|c|c|c|}
\hline Case Studies & Holmes et al. $[25]-\mathrm{A}$ & ey $[26]-B$ & Messner et al. [27]-C & ad Drechsler $[28]-D$ \\
\hline $\begin{array}{l}\text { Participatory } \\
\text { settings }\end{array}$ & $\begin{array}{l}\text { Two types of focus group sessions: With } \\
\text { experts to characterize relationships } \\
\text { between ecosystems and their services } \\
\text { and selected indicators; and (four } \\
\text { sessions) with citizens to design CV } \\
\text { surveys and predict results. Ninety-six } \\
\text { respondents (consumers) to CV survey } \\
\text { and statistical adjustment to the regional } \\
\text { population. } \\
\text { Citizen/consumer premises. }\end{array}$ & $\begin{array}{l}\text { Citizen's jury composed of } 13 \text { randomly } \\
\text { selected jurors through phone surveys, } \\
\text { following stratification rules to ensure } \\
\text { representativeness of the regional population. } \\
\text { Five witnesses with particular expertise in } \\
\text { each management activity and two witnesses } \\
\text { on general national park management. The } \\
\text { jury met over three days (preparation, } \\
\text { presentations and deliberation). } \\
\text { Citizen/consumer premises. }\end{array}$ & $\begin{array}{l}\text { Twenty interviews and "snow ball system" } \\
\text { to identify all relevant stakeholders. Group } \\
\text { talk with one stakeholder group (cross-state } \\
\text { group) around climate modeling and policy } \\
\text { strategies and individual discussions about } \\
\text { the impact matrix (CBA step). Deliberative } \\
\text { outranking MCA with all stakeholders. } \\
\text { Stakeholder premises. }\end{array}$ & $\begin{array}{l}\text { Workshops and questionnaires before } \\
\text { the jury. Stakeholder's Jury composed of } \\
\text { five natural resources managers. Four } \\
\text { witnesses (local water authority, local ski } \\
\text { resort, state natural resources } \\
\text { management, member of local } \\
\text { parliamentary council) and a judge } \\
\text { (community psychologist) assisted the } \\
\text { jury during one day. Stakeholder } \\
\text { premises. }\end{array}$ \\
\hline Data & $\begin{array}{l}\text { Computerized CV surveys with } \\
\text { photographs and maps and specific biding } \\
\text { structure (dichotomous choice). } \\
\text { Expressed WTP represent the benefits } \\
\text { associated with each restoration scale, } \\
\text { while costs are estimated on the basis of } \\
\text { similar projects implemented in the } \\
\text { region, through a cost-sharing program } \\
\text { of the Natural Resources } \\
\text { Conservation Service. } \\
\text { Net benefits, associated with marginal } \\
\text { changes in ecosystem services provision. }\end{array}$ & $\begin{array}{l}\text { Deliberation among jury members and } \\
\text { debates with witnesses. Debates } \\
\text { and argumentation around current } \\
\text { management practices, comparison of } \\
\text { alternative management options and } \\
\text { qualitative suggestions. } \\
\text { Individual WTP understood as the maximum } \\
\text { amount that citizens could be charged given } \\
\text { the environmental improvement and the } \\
\text { payment vehicle considered. }\end{array}$ & $\begin{array}{l}\text { Interviews and group talks. Climate change } \\
\text { modeling. Co-production of alternatives } \\
\text { strategies and criteria with decision-makers, } \\
\text { based on interviews, group talks and data } \\
\text { availability. Calculation and ranking of } \\
\text { economic and ecological criteria depending } \\
\text { on the five alternatives and the two } \\
\text { scenarios considered (CBA step). } \\
\text { Individual preferences (weights) identified } \\
\text { by interviews. Arguments during } \\
\text { deliberative step. } \\
\text { Stakeholder preferences, policy } \\
\text { trade-offs, future uncertainties and } \\
\text { consensual alternative. }\end{array}$ & $\begin{array}{l}\text { Preliminary phase (workshops and } \\
\text { questionnaires): Development of } \\
\text { management options, criteria, impact } \\
\text { matrix and preliminary rankings. } \\
\text { Arguments and debates around } \\
\text { witnesses' presentations. Identification } \\
\text { and discussion of juror's preferences } \\
\text { (weights). Use of probabilistic software } \\
\text { (ProDecX) to screen policy alternatives, } \\
\text { discuss weights and to reduce } \\
\text { uncertainty/dissensions around weights. } \\
\text { Sensitivity analysis posterior to the jury. }\end{array}$ \\
\hline
\end{tabular}


Table 1. Cont.

\begin{tabular}{|c|c|c|c|c|}
\hline lies & et al. $[25]-\mathbf{A}$ & mes and Blamey $[26]-B$ & Messner et al. [27]-C & Proctor and Drechsler $[28]-D$ \\
\hline $\begin{array}{l}\text { Valuation } \\
\text { processes }\end{array}$ & $\begin{array}{l}\text { Documentation on the historical } \\
\text { characteristics of the region. } \\
\text { Documentation on the cost-sharing } \\
\text { program for riparian restoration to } \\
\text { determine average costs of restoration } \\
\text { (and the minimum benefits necessary for } \\
\text { economic feasibility). Two types of focus } \\
\text { groups were used for CV surveys design } \\
\text { and for ES indicators, respectively. } \\
\text { Computerized CV. Statistical } \\
\text { analysis. CBA. } \\
\text {-Aggregation- }\end{array}$ & $\begin{array}{l}\text { The jurors are confronted with two charges: } \\
\text { Under the first charge, jurors had to reach a } \\
\text { consensus over three different options of } \\
\text { management activities at constant budget. } \\
\text { Consensus over status quo was reached. } \\
\text { Under the second charge the jury had to } \\
\text { consider improving all management activities } \\
\text { financed by the introduction of a tax on } \\
\text { inhabitants. No consensus was reached } \\
\text { regarding the amount of the tax. A voting } \\
\text { procedure was applied to close the process. } \\
\text {-Consensus and voting- }\end{array}$ & $\begin{array}{l}\text { Historical documentation and interviews. } \\
\text { Development of scenarios and alternatives. } \\
\text { Climate change and future uncertainties } \\
\text { modeling and discussion. Modification of } \\
\text { policy alternatives. Calculation of impact } \\
\text { matrix. Individual discussions over impact } \\
\text { matrix and identification of stakeholder's } \\
\text { preferences (weights). Deliberative MCA: } \\
\text { Individual impact matrixes are presented } \\
\text { and discussed. A consensus has to be } \\
\text { reached over weighting, otherwise new } \\
\text { alternatives are designed and the } \\
\text { subsequent steps repeated. } \\
\text {-Consensual weighting- }\end{array}$ & $\begin{array}{l}\text { Preliminary phase. Discussion around the } \\
\text { outcomes after first ranking process } \\
\text { showing strong dissensions among } \\
\text { jurors. Witnesses' interventions. } \\
\text { Replacement of the ranking process by a } \\
\text { proportional weighting. Redefinition of } \\
\text { the ES and social criteria. Discussion of } \\
\text { new outcomes and justification of the } \\
\text { weights assigned by jurors. Choice of a } \\
\text { policy strategy. Sensitivity analysis } \\
\text { showing a higher level of consensus. } \\
\text {-Ranking and proportional weighting- }\end{array}$ \\
\hline $\begin{array}{l}\text { Outcomes for } \\
\text { decision-making }\end{array}$ & $\begin{array}{l}\text { Annual economic benefits (median WTP) } \\
\text { for each restoration scale. Full restoration } \\
\text { has the highest benefit/cost ratio. } \\
\text { Decision-makers know that the biggest } \\
\text { public benefits are associated with full } \\
\text { restoration, on the basis of the restoration } \\
\text { program in place (average costs) and the } \\
\text { demands of the population } \\
\text { (WTP statements). }\end{array}$ & $\begin{array}{l}\text { Insights about current management } \\
\text { alternatives. Arguments and counter } \\
\text { arguments regarding the introduction of a tax } \\
\text { on inhabitants. Partial agreement on a certain } \\
\text { tax level, with discussions over equity issues. } \\
\text { Possibility of including the WTP results in a } \\
\text { CBA, comparing the amount of money that } \\
\text { would be collected by introducing the tax } \\
\text { with an estimation of the costs implied by the } \\
\text { new management strategy. }\end{array}$ & $\begin{array}{l}\text { Ideally, the process is able to assess and } \\
\text { evidence for a consensual alternative for } \\
\text { decision-making, taking into account } \\
\text { weighted economical and ecological } \\
\text { dimensions as well as inequalities in the } \\
\text { balance of power between stakeholders and } \\
\text { global external futures changes } \\
\text { (socioeconomic and climate) over a } \\
\text { conflicting situation. However, only the } \\
\text { results of the CBA step are discussed in } \\
\text { the paper. }\end{array}$ & $\begin{array}{l}\text { Exchange of arguments and elicitation of } \\
\text { decision-makers' preferences through } \\
\text { weighting. Confirmation (after criteria } \\
\text { redefinition) of a management option. } \\
\text { After the process, decision-makers have } \\
\text { another conception of the specificities of } \\
\text { the problem considered. The confirmed } \\
\text { management option is based on a higher } \\
\text { degree of consensus than before } \\
\text { the process. }\end{array}$ \\
\hline
\end{tabular}


Table 1. Cont

\begin{tabular}{|c|c|c|c|c|}
\hline Case Studies & Holmes et al. $[25]-\mathbf{A}$ & James and Blamey $[26]-B$ & Messner et al. $[27]-\mathrm{C}$ & Proctor and Drechsler [28]-D \\
\hline Limits & $\begin{array}{l}\text { Challenges in linking ecosystem science } \\
\text { with social values; difficulties in } \\
\text { communicating complex ecological } \\
\text { issues. CV respondents had trouble } \\
\text { understanding how ecosystems should be } \\
\text { valued (as substitutes or complementary). }\end{array}$ & $\begin{array}{l}\text { Numerous issues are discussed: compliance } \\
\text { behaviours, equity between jurors' } \\
\text { contributions, inconsistencies between citizen } \\
\text { framing and individual WTP elicitation, } \\
\text { WTP interpretation, introduction of the } \\
\text { voting procedure, articulation of CBA results } \\
\text { and representativeness. }\end{array}$ & $\begin{array}{l}\text { The authors underline that the process does } \\
\text { not fully meet the ideal claims on which it } \\
\text { is based, regarding the participation debate. } \\
\text { However, it improves the decision-making } \\
\text { process in terms of competence and } \\
\text { fairness. Other important limits concerning } \\
\text { time spending and costs are mentioned. }\end{array}$ & $\begin{array}{l}\text { The authors mostly highlight problems } \\
\text { with the software used for the weighting } \\
\text { process and for the presentation of the } \\
\text { outcomes to the jurors. They underline } \\
\text { the necessity to discuss in details criteria } \\
\text { and impact matrix as well as the } \\
\text { importance of the iterative nature of the } \\
\text { process. }\end{array}$ \\
\hline
\end{tabular}


Although the cases present a great heterogeneity in their objectives and contexts, a first point is that all of them are related to ecosystem degradation and land-use conflicts between various social groups. In all cases, a complex environmental choice has to be made considering an intended improvement of ecological conditions and a local development perspective, involving economic and social costs and benefits. However, if all of the cases studied are viewed by their authors as empirical tests of specific environmental valuation methods aiming at answering scientific research goals, then cases A, C and D are more directly concerned with a real policy issue than case B. Case B was implemented as an experimental test on deliberative monetary valuation.

\subsection{Addressing the Cognitive, Normative and Composition Problems}

This section focuses on the cases as empirical attempts to improve environmental valuation processes, by implementing them in participatory settings. The results are summarized in Table 2.

Table 2. Comparative analysis of the cases regarding the cognitive, normative and composition problems.

\begin{tabular}{ccccc}
\hline & A & B & C & D \\
\hline Cognitive & Low $/ \mathrm{P}$ & High & High * & High * \\
Normative & NSA & Medium & Medium $/ \mathrm{P} *$ & High * \\
Composition & Low & $\mathrm{P}$ & High * & High * \\
\hline
\end{tabular}

NSA indicates "No Sensible Attempt" to address the issue considered; P indicates that the method could have been designed to address the issue but that it was not the case in the study considered; * indicates that because of the combined nature of the process, it is hard to assess whether the treatment of the problem was due to the participatory setting.

\subsubsection{The Cognitive}

In case A, cognitive issues were addressed through two main avenues: First, citizen focus group sessions were conducted with the aim of improving the framing of the information included in CV surveys (for instance, participants were presented with a matrix showing the level of ES provision associated with the different restoration scales), and second, the authors argue that using computerized instruments helped ensuring a better understanding of the bidding structure. However, in CV, individual preferences are considered as already given. In case A, the participatory setting did not attempt to address the issue of preference construction: Most of the respondents to the CV surveys did not participate in the focus group sessions. This explains the lower capacity to address cognitive issues in case A. More generally, attempting to address the preference construction problem by combining $\mathrm{CV}$ and focus groups would be problematic in our view because the logic of statistical representativeness implied by $\mathrm{CV}$ and the narrower format of the focus group setting would come into conflict.

In contrast, in case $\mathrm{B}$, cognitive issues were seriously taken into account because of the deliberative setting: The jury took two days to deliberate, which certainly helped with the elicitation and construction of preferences. Furthermore, the authors discuss in depth how information should be provided to the jurors. They conclude in support of unlimited access to witnesses and propose to rely on one additional neutral witness dedicated to helping the jury with informational issues. 
In case $\mathrm{C}$, several interviews and group talks were conducted for problem analysis, the identification of relevant stakeholders and the design of policy strategies, indicators and scenario development (Table 1). This long phase of participatory preparation was very interactive, which probably already induced cognitive effects, i.e., changes in the way each stakeholder perceived the situation. Furthermore, the cognitive dimension was addressed both during the single-criterion and MCA steps. The single-criterion valuation is a matrix measuring the quantified impacts of economic and ecological criteria dependent on the policy alternatives considered (Table 1). The authors name it CBA because it calculates and presents the rankings of all policy strategies with respect to each single criterion. The information structure is close to that of MCA, but no overall ranking or weighting of the criteria takes place. The point is to elicit trade-offs between policy alternatives and to make them salient in the minds of participants. The authors plan to discuss the CBA results and to collect preliminary individual weightings through interviews. Afterwards, during the MCA step, individual impact matrixes would be presented and the objective of the deliberation would be to attain a consensual weighting. If no consensus is attained, the process should be repeated. We conclude that the procedure used in case $C$ has a high capacity to address cognitive issues, both because of the CBA/MCA structuring and because of the deliberative nature of the process.

In case $\mathrm{D}$, management options and criteria (Table 1) were developed and discussed during a group talk prior to the jury, and questionnaires were sent to agree on the global objectives of the study and to identify preliminary individual rankings. Cognitive issues were especially addressed during the subsequent deliberative MCA step. First, jurors' perception of the situation was confronted with witnesses' presentations, after which debates, exchanges of views and arguments took place. This certainly had great cognitive impacts. Second, the MCA framing allowed the structuring information around an impact matrix showing quantified (cardinally and ordinally) relationships between criteria and policy strategies. The software used allowed the jurors to be aware of each other's individual preferences for the ranking of criteria. Furthermore, the integration of MCA and deliberation allowed the jury to discuss the results of the first ranking, choosing to modify the criteria structure and the weighting process along the way. The higher degree of consensus attained at the end of the process over a policy strategy can be understood as a positive consequence of the preference construction process. Similarly to $\mathrm{C}$, the quality of the treatment of cognitive issues appears strongly related to both the deliberative setting and the MCA structuring.

We can conclude that in cases B, C and D, the participatory settings greatly helped to address cognitive issues.

\subsubsection{The Normative}

CV postulates commensurability. By definition, dealing with the normative problem is problematic. Furthermore, WTP results are used in CBA, which implies compensability. Interestingly, however, the scenario of local taxes increase proposed to CV respondents (WTP amounts were asked in terms of an increase in local sales taxes for different levels of riparian restoration) aimed to ensure the credibility of the amounts bid, and this procedure probably helped avoiding the potential reluctance of participants to state their preferences in monetary units. We did not find any information concerning the occurrence or treatment of 0-bids and/or non-responses, and it remains unclear in the study whether the respondents would feel comfortable with the interpretation of their WTP statements (i.e., the measure of the social welfare that the environmental improvement considered would create for them). 
In deliberative monetary valuation, the normative problem is generally a core issue. On the one hand, the process of WTP elicitation implies commensurability, i.e., narrowing-down preferences to the expression of a monetary number. On the other hand, deliberative monetary valuation allows participants to think openly about their choices. In case B, as the process was designed to open the possibility of using the results in CBA, compensability was also assumed. The normative problem arose during the second charge, when the jurors were asked how much they would be willing to pay (in terms of a local tax increase) to improve all types of management activities. As in case A, the proposed scenario probably improved the credibility of WTP statements and helped avoiding the potential reluctance of participants to express monetary values for environmental attributes. The authors report that some jurors had trouble understanding the notion of individual WTP. Indeed, some jurors tended to adopt a "contribution model", instead of the "purchase model" typically assumed in CV and CBA: They wished to know how much it would cost to improve all management activities to make a decision about the amount of the tax. Because the process allowed jurors to exchange views and arguments, both about the problem considered and about what was asked them (e.g., the meaning of WTP statements and their expected use), the deliberative setting helped to raise and resolve normative issues. Because the deliberative monetary valuation process allows a certain degree of reflection upon WTP elicitation, we assign this procedure a medium capacity to address the normative problem.

The normative problem has a different form in cases $\mathrm{C}$ and D compared with cases A and B because the economic dimension is not based on WTP statements. Case $\mathrm{C}$ postulates commensurability and high comparability: The measurements included in the impact matrix are cardinal numbers. However, the MCA method used (PROMETHEE (Preference Ranking Organisation METHod for Enrichment Evaluations)) implied non-compensability. One interesting feature of the method used in case $\mathrm{C}$ is that the method allowed adjusting the assumptions regarding the normative problem to the considerations of the stakeholders involved. For instance, the use of economic net benefits was suggested and agreed upon by the stakeholders involved during the preliminary phase. This explains why we conclude for a medium capacity to address the normative problem in case B, without excluding the possibility for the method to be designed differently.

The same outranking method (PROMETHEE) was used in case D, and the economic costs and benefits were measured on the basis of existing data, depending on each policy alternative. The costs were mainly in terms of the establishment of facilities, weed control, fencing, lost incomes and visitor fees, while the benefits included increased incomes of tourist operators and accommodation providers. Case D implied a weaker form of commensurability compared with case $C$ : The impact matrix included cardinal quantification, binary indexes and ordinal indexes. The criteria (Table 1) were also designed by the jurors at the beginning of the process, during the preliminary phase and during the jury. The jurors also decided to modify the weighting procedure to give the same importance to the three broad categories of criteria (economic, social and ES). We assign this procedure a high capacity to address normative issues, both because of the MCA structuring and because of the deliberative nature of the process.

We can therefore conclude that for cases B, C and D, the deliberative setting had positive effects on normative issues, but for very different reasons. As we noted in case $\mathrm{B}$, the normative problem related to WTP statements did not disappear, but participants had time to think collectively about what was requested of them. In cases $\mathrm{C}$ and $\mathrm{D}$, the normative issues depended on both the MCA structuring and the deliberative setting: The latter allowed adjusting the assessment to the considerations of the participants. 


\subsubsection{The Composition Problem}

In case $\mathrm{A}$, the focus groups sessions conducted with experts helped to address the composition problem through the characterization of the relationships between ecosystems and their services. Five categories of ecosystem services and their indicators were adopted (Table 1). The study did not attempt to offer precise quantifications of the level of ecosystem services provision associated with each restoration scale. Instead, the CV respondents were confronted with broad categories (low, moderate, high). One of the main results of the study was that the issue of scale can be taken into account in CV and that the benefits associated with ecosystem services provision are "super-additive" (i.e., there is a holistic effect associated with the restoration scale). However, we should note that the study selected specific positively interdependent ecosystem services. This implies that the potential trade-offs between restoration activities and the other services that river banks provide are not taken into account. The authors conclude that "much remains to be done to improve methods for communicating complex ecological dynamics in the context of economic valuation studies" (p. 29), which indicates that both the cognitive and composition problems remain problematic.

In contrast, the composition problem is not particularly discussed in case B: The study focuses on changing management practices without attempting to precisely measure the expected effects of those changes on ecosystems (see in Table 1). In that sense, the composition problem was partly avoided. However, witnesses were experts in particular management activities. A dialogue between jurors and witnesses regarding ecological complexity, interdependencies, etc. could thus have occurred, but the authors do not document this point.

The composition problem was seriously considered in case $\mathrm{C}$, but through climate change modeling than through the design of the ecological criteria: The latter were selected because of their relevance for the stakeholders involved (Table 1). The modeling was realized by the research team after the first round of interviews and group talks. Before the CBA phase, a group talk was organized during which uncertainties and failures related to the specific scientific models used were discussed. Therefore, the composition problem was addressed more through the use of the modeling tool than because of the participatory approach. However, the latter certainly helped raise and resolve cognitive issues related to the integration of modeling.

Finally, the composition problem was addressed in case D through the definition and redefinition of the ecosystem services criteria during the process. The nine ecosystem services criteria identified at the start were merged into four because they were considered redundant by the jurors after witnesses' presentation and the first criteria ranking. In that sense, the composition problem was addressed because the MCA provided information structure and quantifications and because the deliberative context helped the jurors to have a better understanding of the ecological interdependencies entering into play.

Overall, participatory settings proved able to better address the composition problem in all of the cases considered. However, except in case D, the selection of ecological indicators often relied on the choices made by the research teams or on the involvement of experts, rather than on the preferences of the participants involved. 


\subsection{Participation and Decision-Making: Issues and Differences between the Cases Considered}

Attempting to improve valuation methods by introducing participation implies that the quality and legitimacy of the outcomes become dependent on how participation is framed. We noted four important criteria: The role models assumed by participants; the differences in contribution among participants; the level of participatory impact, and the level of democratization of the decision-making process. Table 3 summarizes our analysis for the case studies considered.

Table 3. Comparative analysis of the cases regarding participation criteria.

\begin{tabular}{ccccc}
\hline & A & B & C & D \\
\hline $\begin{array}{c}\text { Role models assumed by } \\
\text { participants }\end{array}$ & $\begin{array}{c}\text { Consumers } \\
\text { and Citizens }\end{array}$ & $\begin{array}{c}\text { Citizens and } \\
\text { Consumers }\end{array}$ & Stakeholders & Stakeholders \\
\hline Differences in contribution & Medium & Low & Medium & Low \\
\hline Level of participatory impact & Consultation & Consultation & Collaboration & Collaboration \\
\hline $\begin{array}{c}\text { Level of democratization of } \\
\text { the decision-making process }\end{array}$ & Low & Low/NA & Medium & Low \\
\hline
\end{tabular}

NA indicates "Not applicable" to the case considered.

\subsubsection{The Role Models Assumed by Participants}

Considering the overall process, the role assumed by the participants in case A varied depending on the stages of the process: Participants were considered as citizens (representatives of the general population) during the focus group sessions, but as consumers during $\mathrm{CV}$ surveys. The choice of the $\mathrm{CV}$ method presumes that the most important decision-making criterion is the economic welfare of the general population considering the given environmental improvement. In other words, the actors or stakeholders that could be the most affected by the decision taken (e.g., local farmers, river bank owners, etc.) do not get a voice as such in the process, which contrasts with the other cases considered.

In case B, the roles assumed by the participants were unclear, as is typically the case in deliberative monetary valuation. Participants were citizens, selected following stratification rules and they were asked to act as representatives of the general interest. They were given information reflecting socioeconomic data of the general population for the elicitation of WTP. The citizen framing implicitly refers to participants as social individuals, able to make value judgments, face hard choices and debate a political issue. However, the elicitation of WTP induces participants to respond as consumers. The authors note that some jurors had trouble understanding the notion of individual WTP and report that some conflict emerged between the citizen's jury framing and the objective of eliciting individual WTP.

In case $\mathrm{C}$, participants consisted of a variety of stakeholders, including federal, state and city decision-makers, public facility representatives, mining, energy and fish-farming industry representatives, a state-owned restoration company, and other civil society actors such as farmer and local tourism associations. Stakeholders therefore included both different categories of representatives of the political authorities in charge and other groups of economic actors and residents connected to the issue at hand. Participants had a clear idea of who was involved and why: The specific interests of stakeholders involved were framed and displayed through the impact matrix. Considering the valuation criteria, the economic language was dominant in the study. The authors of study $\mathrm{C}$ explain that this was the result of a consensus 
that emerged between the stakeholders and that the methodology allowed the positions of the affected parties to be made more explicit and to eventually take into account the interests of the least favored groups.

In case D, participants were also stakeholders, but the jury was only composed of five resource managers, chosen because of their involvement in another ecosystem services valuation project in the region, as well as in the development of a management strategy regarding tourism. Case D was unique in that the jury was composed entirely of formal decision-makers working within the institutional structures in charge of management. Some particularly affected stakeholders (e.g., the local ski resort representative, the water management authority, etc.) were heard by the jury as witnesses, but the process does not guarantee that all relevant stakeholders were heard and does not aim to represent citizens.

We can conclude that the type of actors involved and the role models assumed by the participants in the cases study vary greatly. In cases A and B, participants assumed both the role of consumers and citizens, which created confusion. Consumer and citizen premises imply to give a stronger voice in the process either to the economic benefits of the general population, or to the opinion of the general population, respectively. By contrast, stakeholder premises often entail stronger consideration of the interests of the affected parties. In both cases $\mathrm{C}$ and $\mathrm{D}$, the participants were stakeholders, but the array of participation was nevertheless very different.

\subsubsection{The Differences in Contribution between Participants}

In case A, differences in contribution are justified by the logic of the valuation: The role of the citizens and experts involved in the focus groups was limited to the design of CV surveys and to the choice of the ecosystem services indicators. During the CV assessment stage, however, the differences in contribution between respondents were low because all participants were confronted with the same questionnaire. We therefore conclude for a medium level of differences in contribution in case A.

In case B, the jury constituted the heart of the assessment. For this reason, attempting to maintain a sufficient level of equity in contribution among participants during this stage was very important, and the authors paid a serious attention to this issue. Indeed, they argue that, in theory, deliberation should guarantee "equal standing and effective voice" for every citizen involved (p. 237). However, they also recognize that this ideal was not achieved during the study. Various sources of inequality in contribution are discussed (e.g., social and cognitive skills and capacities, prior knowledge, etc.), and this issue is viewed as fundamental for participatory processes in general.

In case $\mathrm{C}$, the different groups of involved stakeholders contributed unequally throughout the entire process. Indeed, one particular group of stakeholders, the cross-state group, composed of representatives of local and national political authorities, had a dominant role. This stakeholder group was the only one involved in the workshops in which climate modeling was discussed and policy strategies and criteria were designed. It was also the only group of stakeholders to be involved in the single-criterion assessment. However, an important feature of the participatory study is that all stakeholders, including farmer and local tourism associations, as well as mayors of small cities near the river, etc. should normally take part in the decision-making process during the final MCA stage. It is highly unlikely that those actors would have been involved in decision-making without the implementation of study $\mathrm{C}$. The issue of equity in contribution is seriously taken into account throughout the valuation process and is discussed in-depth by the authors in case C. During the final deliberative MCA assessment, the process should 
structurally guarantee equity in contribution; individual impact matrixes should be presented and discussed to attain a consensus over weighting. Therefore, we assign case $\mathrm{C}$ a medium level of equity in contribution considering the overall process: The large array of participation implied that this issue was more difficult to handle, although the MCA structure and the deliberative setting provided great help.

In case $\mathrm{D}$, all of the stakeholders participated to the decision-making process. Equity in contribution was insured through the MCA structuring: Individual impact matrixes were presented and discussed with the purpose of reaching consensus over the appropriate weighting and policy strategy. Furthermore, during the second visualization of results, each juror was asked to justify their positioning and to explain the reasons underlying his/her weighting. We conclude for a high equity in contribution in case $\mathrm{D}$, to which the deliberative process and the MCA structuring contributed. However, compared with case C, the higher degree of equity in contribution did not arise from methodological differences, but rather from the choices made regarding who was involved in the valuation and to existing differences between the institutional contexts in which the valuation processes took place.

Considering the process as a whole, both studies B and D managed to achieve a rather low level of differences in contribution, while we conclude for a medium level in studies A and C (for very different reasons). Deliberative MCA presents great advantages to deal with this issue, especially during the assessment phase.

\subsubsection{The Level of Participatory Impact}

CV typically implies consultation. In case A, the objective was to inform the political structures in charge of management on the efficiency of public investment in riparian restoration in the area considered. The inclusion of focus groups did not increase the level of participatory impact: Participants involved in the focus group were not consulted for problem scoping or for the design of policy alternatives, but only for CV survey design. A specificity of case A is that participants in both the CV surveys and the focus groups were treated as external subjects who were to be analyzed from a "neutral" point of view, and whose contribution was required only for assistance and data gathering. This contrasts with the other cases in which participants were treated as political individuals, able to make choices and to be further involved in the decision-making process.

In case B, the level of participation impact is hard to assess because of the fictional character of the study and because of the ambiguities of deliberative monetary valuation. Indeed, the authors state that the deliberative monetary valuation exercise was designed to provide results, which could be included in a CBA. For instance, it means that jurors followed a "purchase model" and not a "contribution model" (p. 238): They were not told how much the environmental improvement would cost when confronted with the WTP question. The objective of producing results to be used in a CBA implies that the goal of the study was rather providing information for the institutions in charge of management than making a political choice about the management options considered. This explains why we consider that the level of participation impact in B was consultation, as in case A. However, through the deliberative framework, participants had a higher degree of control over the outcomes of the process compared with A. Furthermore, participants were treated as political individuals able to face hard choices, information flows were very interactive and participants had to reach a consensus over a preferred management option during the first part of the exercise. The status of the deliberation (i.e., the qualitative insights about the preferences of 
participants regarding the various management options considered) remains ambiguous in case B: Should the debates preceding WTP elicitation be considered instrumental (i.e., viewed as a "trick" to elicit socially constructed WTP), or would their contents have mattered per se for decision-making?

In cases $\mathrm{C}$ and $\mathrm{D}$, the level of participation impact was collaboration because both processes were very interactive and information flows were shared between participants. Furthermore, participants had a strong control over the outcomes of the process and a strong influence on both policy alternatives and on the decision per se.

We can conclude that the level of participation impact was clearly stronger in cases $C$ and $D$ than in case $\mathrm{A}$ and $\mathrm{B}$, although the latter remains ambiguous regarding this point.

\subsubsection{The Level of Democratization of the Decision-Making Process}

In case $\mathrm{A}$, the history of the environmental problem considered is well documented, and the study concludes for both the scientific community (the dimension of scale can be taken into account in $\mathrm{CV}$ and CBA as an indicator of ecosystem services provision) and for the institutional decision-makers in the region (the optimal solution is full restoration, which has the best cost-benefit ratio). The focus groups were only implemented as an aid to the expertise of the analysts and to assist the research team. Institutional structures in charge of management are understood as sovereign decision-makers who can decide whether to take into account the outcomes of the study. The goal was not to provide opportunities for the local population to be further engaged in environmental decision-making, and the level of democratization of the decision-making process is therefore low.

In case $\mathrm{B}$, the level of democratization of the decision-making process is unclear. Indeed, the authors state that one of their objectives is "incorporating community attitudes and values into decision-making" (p. 225). Topics such as participatory democratic theory and deliberative and discursive democracy are discussed. However, at the same time, the process was framed to provide a sounder elicitation of WTP estimates at the service of external political bodies, in a configuration close to that of case A. The citizens' framing presented an opportunity to democratize the decision-making process and to foster the level of participation impact. This would have implied to discharge, at least partly, the management authorities of their decision-making power. For instance, their implication in the study as witnesses would have enforced the legitimacy of the process, but the decision-making would have operated beyond their reach. However, in that perspective, what could motivate the political authorities to participate in the process, and does monetary valuation still have a purpose? This indicates a problematic aspect of deliberative monetary valuation: Tensions arise between the normative claims of deliberative democracy and the goal of providing useful economic estimates for existing institutional structures. It also raises questions regarding the engagement of political authorities in deliberative valuation (e.g., are the political authorities willing to engage, why, how etc.).

In case $\mathrm{C}$, the authors insist on the need to offer "practicable science-based decision support processes" (pp. 63-64) for environmental problem solving. The goal of the study was to improve decision-making in terms of competence and fairness through the development of a participatory process. The implementation of participation initially relied on the will of the political authorities themselves, who implemented a preliminary participatory initiative, from which the formation of the cross-state group resulted. Because of study $\mathrm{C}$, however, the diversity of the stakeholders involved in the decision-making process increased 
greatly. On the one hand, the fact that a specific group of stakeholders, the cross-state group, played a dominant role in the process contrasts with the ideal of deliberative democracy and with the objective of transferring decision-making power to citizens. But on the other hand, study $\mathrm{C}$ fostered the will and the capacity of the political authorities to engage in a large participatory process. We therefore conclude for a medium capacity of democratization.

By contrast with case $\mathrm{C}$, in case $\mathrm{D}$ all of the participants were representatives of the political authorities in charge of management. The main outcome of the study for decision-makers was not only the confirmation of a policy strategy but also the insurance that the degree of consensus over the choice of this strategy was higher at the end of the process than before. However, we conclude for a low degree of democratization of the decision-making process: The study was not designed to allow the inclusion of all affected or interested stakeholders, or to foster the engagement of citizens. Some affected stakeholders intervened as witnesses, but they did not took part in decision-making. We can conclude that from all the cases considered none attained a high level of democratization of the decision-making process. This dimension varies across studies for different reasons. Cases A and D did not aim at fostering this dimension because they were designed as decision-aid tools, which contrasts with cases B and $\mathrm{C}$. From the latter we can conclude that designing processes involving political authorities, while trying to foster the engagement of other stakeholder groups in decision-making is a delicate operation. However, case $\mathrm{C}$ illustrates that deliberative MCA can provide a great help in that task. Regarding case $\mathrm{B}$, we can conclude that deliberative monetary valuation proved ambiguous: The purpose of involving citizens in decision-making contrasts with the objective of producing a monetary estimate.

\section{Conclusions}

Aligned with previous research results $[9,14,15,17]$, our analysis confirms that non-deliberative and deliberative participatory methods are relevant means to address the complexity involved in environmental valuation and to reduce the shortcomings of traditional decision-making methods. In the cases considered, participation often helped participants to address the cognitive, normative and composition problems. Overall, deliberative multicriteria evaluation showed a great potential to address cognitive and normative issues because it allows the problem structure to be made more explicit and salient in the minds of participants, and provides time for preference construction without necessarily forcing trade-offs across value dimensions. However, even combined with deliberation, the cognitive and normative problems remain for monetary valuation (and especially for stated preference methods, such as contingent valuation, which was analyzed through the cases considered). Regarding the composition problem, we note that the design of indicators often tends to remain strongly dependent on the choices made by the research team and on the involvement of experts. However, cases C and D showed that highly interactive processes involving deliberation have good potential to address this issue, especially because they produce a collective reflection on the matter and allow for the chosen indicators to be adapted to the needs and wills of the participants involved, while fostering their understanding of the various dimensions of the problem under consideration.

Participation may therefore help to address the complexity involved in environmental valuation, and yet it nevertheless covers a great variety of processes, associated with specific purposes, which can influence all dimensions of value articulating institutions (who is involved, what counts as data, how are 
they articulated, etc.). The quality and legitimacy of the outcomes of valuation processes become strongly dependent on how participation is framed. Based on the literature and the analyzed case studies, we showed that the roles assumed by participants, the differences in contribution between participants, the level of participation impact and the level of democratization of the decision-making process are important criteria useful to assess complex valuation processes, combining non-deliberative and deliberative participatory features with classical methods such as CV, CBA and MCA. Our analysis suggests that those criteria are strongly interdependent, but not systematically positively correlated. Furthermore, we note that those issues are strongly related to the institutional and political contexts in which valuation studies take place.

Indeed, our analysis suggests that both cases A and D were designed as decision-aid tools, aiming at providing expertise and scientific structuring for a decision-making power that remains sovereign. By contrast, in case $\mathrm{C}$, some stakeholders who were not institutional decision-makers had a stronger influence on decision-making during the study. Case B remains ambiguous regarding this point: The involvement of citizens offered a great opportunity to increase the level of participation impact and the level of democratization of the decision-making process, but the valuation was framed to produce a monetary estimate useful for the institutional authorities in charge of management, whose decision-making capacity has not been further engaged in the valuation process. What contrasts between cases $\mathrm{A}$ and $\mathrm{D}$, however, is that in D participants and decision-makers (i.e., both the jurors and the witnesses) were treated as political individuals upholding values as well as particular interests and capable of reasoning and arguing.

Participatory and especially deliberative environmental valuation methods therefore still face numerous issues: Designing processes involving both citizens and stakeholders, including representatives of political authorities in charge, in a situation of conflict is a delicate operation. From a theoretical perspective, the field of participatory environmental valuation seems to be at a crossroads between, on the one hand, the normative claims of deliberative democracy advocating the empowerment of citizens as a means for values transformation towards sustainability, as well as the necessity to valorize political forms of decision-making, i.e., the expression of value judgments and arguments, and, on the other hand, the need to develop technical tools and processes aiming at fostering the engagement of political authorities and institutional structures in environmental decision-making. Indeed, the engagement of political authorities can be seen as a necessity, in order to insure that the results of valuation studies have an impact in "real-life", but it can also constrain the ability to effectively democratize decision-making.

Our analysis also shows that if participation is generally regarded as a means to reduce technical shortcomings of methods, such as CV and MCA, implementing participatory, and especially deliberative processes, implies considering core institutional and political issues, such as who has the ability to make a decision during the process, at which conditions the political authorities in charge are willing to engage in participatory valuation processes, how to insure that the outcomes of the valuation process will effectively be taken into account within decision-making, etc. Therefore, the effectiveness of environmental valuation tends to become increasingly dependent on contextual and political dimensions.

\section{Acknowledgments}

We would like to thank Arild Vatn for organizing the Thor Heyerdahl Summer School in Environmental Governance, which took place in the Norwegian University of Life Sciences in 2012, 
during which the design of this research was elaborated. The work carried out for this paper was partly supported by the Portuguese Science and Technology Foundation (FCT) through the Scholarship SFRH/BD/68846/2010.

\section{Author Contributions}

Each co-author of this paper contributed equally to the design and the data analysis of the reported research. The first author led the development of the final version of the analytical framework and the writing of the paper.

\section{Conflicts of Interest}

The authors declare no conflict of interest

\section{Reference}

1. MEA-Millennium Ecosystem Assessment. Ecosystems and Human Well-being Synthesis; Island Press: Washington, DC, USA, 2005.

2. TEEB - The Economics of Ecosystems and Biodiversity. Ecological and Economic Foundations; Earthscan: London, UK, 2010.

3. Norgaard, R.B. Ecosystem services: From eye-opening metaphor to complexity blinder. Ecol. Econ. 2010, 69, 1219-1227.

4. Spash, C.L. How much is that ecosystem in the window? The one with the bio-diverse trail. Environ. Values 2008, 17, 259-284.

5. Martinez-Alier, J.; Munda, G.; O’Neill, J. Weak comparability of values as a foundation for ecological economics. Ecol. Econ. 1998, 26, 277-286.

6. Ropke, I. Trends in the development of ecological economics from the late 1980s to the early 2000s. Ecol. Econ. 2005, 55, 262-290.

7. Spash, C.L. The development of environmental thinking in economics. Environ. Values 1999, $8,413-435$.

8. Zografos, C.; Howarth, R.B.; (Eds.) Deliberative Ecological Economics; Oxford University Press: Delhi, India, 2008.

9. Zografos, C.; Howarth, R.B. Deliberative Ecological Economics for Sustainability Governance. Sustainability 2010, 2, 3399-3417.

10. Farber, S.C.; Costanza, R.; Wilson, M.A. Economic and ecological concepts for valuing ecosystem services. Ecol. Econ. 2002, 41, 375-392.

11. Wallace, K.J. Classification of ecosystem services: Problems and solutions. Biol. Conserv. 2007, 139, 235-246.

12. Costanza, R. Ecosystem services: Multiple classification systems are needed. Biol. Conserv. 2008, $141,350-352$.

13. Jacobs, M. Environmental Valuation, Deliberative Democracy and Public Decision-Making. In Valuing Nature? Economics, Ethics and Environment; Foster, J., Ed.; Routledge: London, UK, 1997; pp. 211-231 
14. Vatn, A. Institutions and the Environment; Edward Elgar: Northampton, MA, USA, 2005.

15. Vatn, A. An institutional analysis of methods for environmental appraisal. Ecol. Econ. 2009, 68, 2207-2215.

16. Gasparatos, A.; Scolobig, A. Choosing the most appropriate sustainability assessment tool. Ecol. Econ. 2012, 80, 1-7.

17. Reed, M.S. Stakeholder participation for environmental management: A literature review. Biol. Conserv. 2008, 141, 2417-2431.

18. Kallis, G.; Videira, N.; Antunes, P.; Pereira, A.G.; Spash, C.L.; Coccossis, H.; Quintana, S.C.; del Moral, L.; Hatzilacou, D.; Lobo, G.; et al. Participatory methods for water resources planning. Environ. Plan. Gov. Policy 2006, 24, 215-234.

19. Videira, N.; Antunes, P.; Santos, R.; Lobo, G. Public and stakeholder participation in European water policy: A critical review of project evaluation processes. Eur. Environ. 2006, 16, 19-31.

20. Lopes, R.; Videira, N. Valuing marine and coastal ecosystem services: An integrated participatory framework. Ocean Coast. Manag. 2013, 84, 153-162.

21. Martín-López, B.; Gómez-Baggethun, E.; García-Llorente, M. Trade-offs across value-domains in ecosystem services assessment. Ecol. Indicat. 2014, 37, 220-228.

22. Kenter, J.O.; O’Brien, L.; Hockley, N.; Ravenscroft, N.; Fazey, I.; Irvine, K.N.; Reed, M.S.; Christie, M.; Brady, E.; Bryce, R.; et al. What are shared and social values of ecosystems? Ecol. Econ. 2015, 111, 86-99.

23. Spash, C.L. Deliberative monetary valuation: Issues in combining economic and political processes to value environmental change. Ecol. Econ. 2007, 69, 690-699.

24. Munda, G. Social Multi-Criteria Evaluation for a Sustainable Economy; Springer-Verlag: Berlin, Germany, 2010.

25. Holmes, T.P.; Bergstrom, J.C.; Huszar, E.; Kask, S.B.; Orr, F., III; Contingent valuation, net marginal benefits, and the scale of riparian ecosystem restoration. Ecol. Econ. 2004, 49, 10-30.

26. James, R.F.; Blamey, R.K. Deliberation and economic valuation, national park management. In Alternatives for Environmental Valuation; Getzner, M., Spash, C., Stagl, S., Eds.; Routledge: London, UK, 2005; pp. 225-243.

27. Messner, F.; Zwirner, O.; Kaskuschke, M. Participation in multi-criteria decision support for the resolution of a water allocation problem in the Spree River basin. Land Use Policy 2006, 23, 63-75.

28. Proctor, W.; Drechsler, M. Deliberative multi-criteria evaluation. Environ. Plan. Govern. Policy 2006, 24, 169-190.

29. Holland, A. Are choices trade-offs? In Economics, Ethics and Environmental Policy; Bromley, D.W., Paavola, J., Eds.; Blackwell Publishing: Oxford, UK, 2002; pp. 17-34.

30. Munda, G. Cost-benefit analysis in integrated environmental assessment: Some methodological issues. Ecol. Econ. 1996, 19, 157-168.

31. Beierle, T. Public Participation in Environmental Decisions: An Evaluation Framework Using Social Goals, Discussion Paper 99-06; Resources for the Future: Washington, DC, USA, 1998.

32. Arnstein, S.R. A ladder of citizen participation. J. Am. Inst. Plan. 1969, 30, 216-224.

33. Kahane, D.; Loptson, K.; Herriman, J.; Hardy, M. Stakeholder and Citizen Roles in Public Deliberation. J. Public Delib. 2013, 9, doi:10.453/27012. 
34. Dryzek, J. Deliberative Democracy and Beyond: Liberals, Critics and Contestations; Oxford University Press: Oxford, UK, 2000.

(C) 2015 by the authors; licensee MDPI, Basel, Switzerland. This article is an open access article distributed under the terms and conditions of the Creative Commons Attribution license (http://creativecommons.org/licenses/by/4.0/). 